\title{
RETROSPECTIVE STUDIES ON BOVINE CALVES AFFECTED WITH CONGENITAL HEART DISEASE
}

\author{
WALAA F. AWADIN \\ Department of Pathology, Faculty of Veterinary Medicine, Mansoura University, Egypt. Postal box: 35516.
}

Received: 31 December 2016;

Accepted: 22 January 2017

\begin{abstract}
Congenital heart disease (CHD) was reported in 4 necropsied calves referred to Mansoura veterinary teaching hospital during the period 2014-2016. The Four necropsied calves suffered from patent foramen ovale (PFO) $(\mathrm{n}=1)$, high ventricular septal defect (HVSD) $(\mathrm{n}=2)$ and persistent ductus arteriosus (PDA) $(\mathrm{n}=1)$. VSD was accompanied by valvular hematoma in 1 calf, hydropericardium, right ventricular hypertrophy and dextroposition of the aorta in another calf. Pasteurella multocida (P. multocida) was isolated from one lung lesion associated with VSD. Histopathological examination of different tissues from necropsied CHD affected calves was made. We concluded that extramedullary hematopoiesis in liver and lymphoid organs besides chronic interstitial nephritis were constant findings associated with CHD in calves.
\end{abstract}

Key words: Congenital heart disease, calves, Egypt

\section{INTRODUCTION}

Congenital heart disease (CHD) in calves was uncommon being observed in only $0.17 \%$ of 50742 bovine hearts inspected in a slaughterhouse study (Van Nie, 1966). In a retrospective study of 2293 calves with congenital anomalies, cardiac malformations occurred in $2.7 \%$ of the cases (Leipold et al., 1972). Ventricular septal defect (VSD) is the most common cardiovascular abnormality in bovine neonates (Fischer and Pirie 1965; Van Nie, 1966; Gopal et al., 1986; West, 1988; Ohwada et al., 2000). Heart defects were diagnosed in 11 of 36 and 7 of 10 calves in 2 separate studies (Leipold et al., 1972; West, 1988). VSD in cattle has also been identified in combination with multiple cardiac defects, such as dextroposition of the aorta (Belling 1961 and 1962; Van Nie, 1966, Sandusky and Smith 1981; West, 1988; Penrith et al., 1994; Gavaghan et al., 2001), persistent ductus arteriosus (PDA) (Cordy and Ribelin, 1950; Sandusky and Smith 1981; West, 1988), patent foramen ovale (PFO) (West, 1988; Penrith et al., 1994; Schwarzwald et al., 2003), PDA (Belling 1961 and 1962), transposition of the great vessels (Sandusky and Smith 1981; West, 1988) and anomaly of the pulmonary (Belling 1961; Schwarzwald et al., 2003) or tricuspid valves (West, 1988). PDA is a persistent patency of a vessel (normally present in the fetus) that connects the

Corresponding author: Dr. WALAA F. AWADIN

E-mail address: walaafekriawadin@yahoo.com

Present address: Department of Pathology, Faculty of Veterinary Medicine, Mansoura University, Egypt. pulmonary arterial system to the aorta. Closure of the ductus arteriosus when breathing commences and placental blood circulation is removed in response to decline pulmonary vascular resistance and increased systemic vascular resistance (Gournay, 2011). The cause of congenital cardiac abnormalities was still unknown. However, it was supposed that CHD may result from injury during development or from single recessive genes or polygenic sets that have lesionspecific effects on cardiac development (Smith, 2009; Jafari Dehkordi et al., 2010). PDA may be accidently found in calves as previously reported during an experiment on an implantable ventricular assist device in Korean calf (Lee and Kim, 2004). In this report we described histopathology of tissues in CHD affected calves and correlated our findings to bacteriological and immunohistochemical parameters.

\section{MATERIALS AND METHODS}

Seven calves referred to Mansoura veterinary teaching hospital, 2014-2016 were necropsied due to severe weakness, respiratory distress or abnormal cardiac sounds. Diagnosis of those anomalies was based on history, clinical examination that was dependent upon visual inspection, auscultation and gross postmortem examination. After internal examination was completed in necropsied calves, tissue samples were collected from different organs and fixed in $10 \%$ neutral formalin. Paraffin sections were made and $5 \mu \mathrm{m}$ sections were cut, mounted on glass microscope slides and stained with hematoxylin and eosin (H\&E). Specimens from infectious lung lesion were sent to bacteriological Lab for isolation. 
In addition, paraffin tissue sections from such lung lesion were placed on positively charged slides (coated slides), deparafinized and dehydrated. After rinsing in PBS, 3\% hydrogen peroxide was applied for 5 minutes to block the endogenous peroxidase. The sections were immunostained using rabbit monoclonal anti-P. multocida antibody with dilution of 1:4000 in PBS. After washing with PBS, slides were incubated at $37^{\circ} \mathrm{C}$ for 45 minutes with Envision and anti-rabbit -horse radish peroxidase labeled polymer kit, DAKO (Carpenteria, CA). The IHC reaction was developed using 3, 3-diaminobenzidine (DAB) (from DAKO Carpenteria, CA) for 5-10 minutes. Sections were counterstained with Mayer's Hematoxylin. Test slides incubated with PBS were used as negative control sections. All slides were examined by light microscopy and the intensity of immunostaining was recorded (Awadin et al., 2012).

\section{RESULTS}

I- Case history and clinical findings:

A diagnosis of CHD was done in 4 calves based on a history of weakness, ill thrift, poor growth and respiratory disease that failed to respond to appropriate therapy. On physical examination, heart murmur was auscultated on the left and right cardiac area. Tachycardia and increase respiratory rate were detected with normal body temperature. No cyanotic mucus membranes were observed in any examined case.

\section{II-Gross findings:}

Necropsy was performed on 4 calves. Cardiac anomalies were identified in all 4 cases as PFO $(n=1)$, PDA $(n=1)$ and VSD $(n=2)$. VSD was located in the upper part of the membranous septum near the aortic root in 2 calves. VSD was accompanied by valvular hematoma in auriculo-ventricular valve in 1 calf, hydropericardium, right ventricular hypertrophy and dextroposition of the aorta in another calf (Figs. $1 \& 2 \mathrm{~A})$. In two calves affected with VSD, necrotic bronchitis (1 calf) and atelectatic lungs (1 calf) were detected (Fig. 2B).

\section{III- Histopathological findings}

Histopathological examination of different tissues from necropsied calves affected with CHD was described as the following:

-Heart in all cases revealed hyaline and hydropic degeneration, focal fibrosis in myocardium, edema and macrophages infiltration in pericardium in one VSD case. Valvular hematoma was a cyst filled with blood and lined by flattened cells surrounded by congested capillaries and mild edema (Fig. 3A-C).

- Lung lesions were seen in two cases with VSD. Diffuse atelectasis was observed in one of them characterized by collapsed alveoli with slit like appearance, lined by cuboidal fetal epithelium (Fig. 3D). Microscopically, necrotizing bronchitis was seen characterized by necrosis and loss of bronchial epithelium, accumulation of necrotic caseated material and basophilic bacterial colonies in lumen of bronchi. Fibrinous exudate plugged lumen of surrounding alveoli (Fig. 4A).

-Liver showed few perivascular mononuclear cells (MNCs) infiltration with mild fibrous tissue proliferation in all cases. MNCs with eosinophils infiltration were seen in portal areas indicating extramedullary hematopoiesis. Hydropic degeneration in hepatocytes, activation of von kupffer cells and dilated sinusoids with RBCs and brown hemosiderin pigment were observed in two cases of VSD (Fig. 5 A\&B).

-Kidneys in all cases showed chronic interstitial nephritis characterized by multifocal interstitial MNCs aggregation and fibrosis. Tubular casts, perivascular fibrosis, brown lipofuscin pigment was seen inside renal epithelium (Fig. 5C\&D).

-Spleen in all cases showed hemorrhage in red pulp and perifollicular granulocytosis. Hemosiderosis in red pulp was found in one case of VSD (Fig. 6A-C).

-Tonsils showed crypt abscess with foci of dystrophic calcification and hypertrophy of lymphoid follicles were seen in all cases (Fig. 6D).

-Lymph nodes were normal in 3 cases and showed lymphoid hypertrophy in one VSD case.

- Pancreas showed remnant of primary islets in case of PDA and interstitial fibrosis in other cases (Fig. $7 \mathrm{~A} \& \mathrm{~B})$.

-Thyroid gland showed nodular lymphocytic aggregation in one case of VSD (Fig. 7C).

-Thymus showed extramedullary hematopoiesis in all cases (Fig. 7D).

-Compound stomach showed only keratin abscesses in one case of VSD.

-Intestinal tract showed normal histological picture in 3 cases and in one case of VSD showed few eosinophils infiltration in mucosa.

\section{IV-Bacteriological findings}

In one case, $P$. multocida was bacteriologically isolated from necrotic bronchitis lesion. On blood agar plate colonies appeared as small mucoid or dry colonies (1-2 $\mathrm{mm}$ in diameter). No hemolysis was detected macroscopically. P. multocida appeared as gram-negative, non-spore-forming coccobacilli with bipolar staining features.

\section{V-Immunohistochemical staining:}

Positive brown immunolabelling for $P$. multocida was detected inside necrotic caseated material (Fig. 4B\&C). 

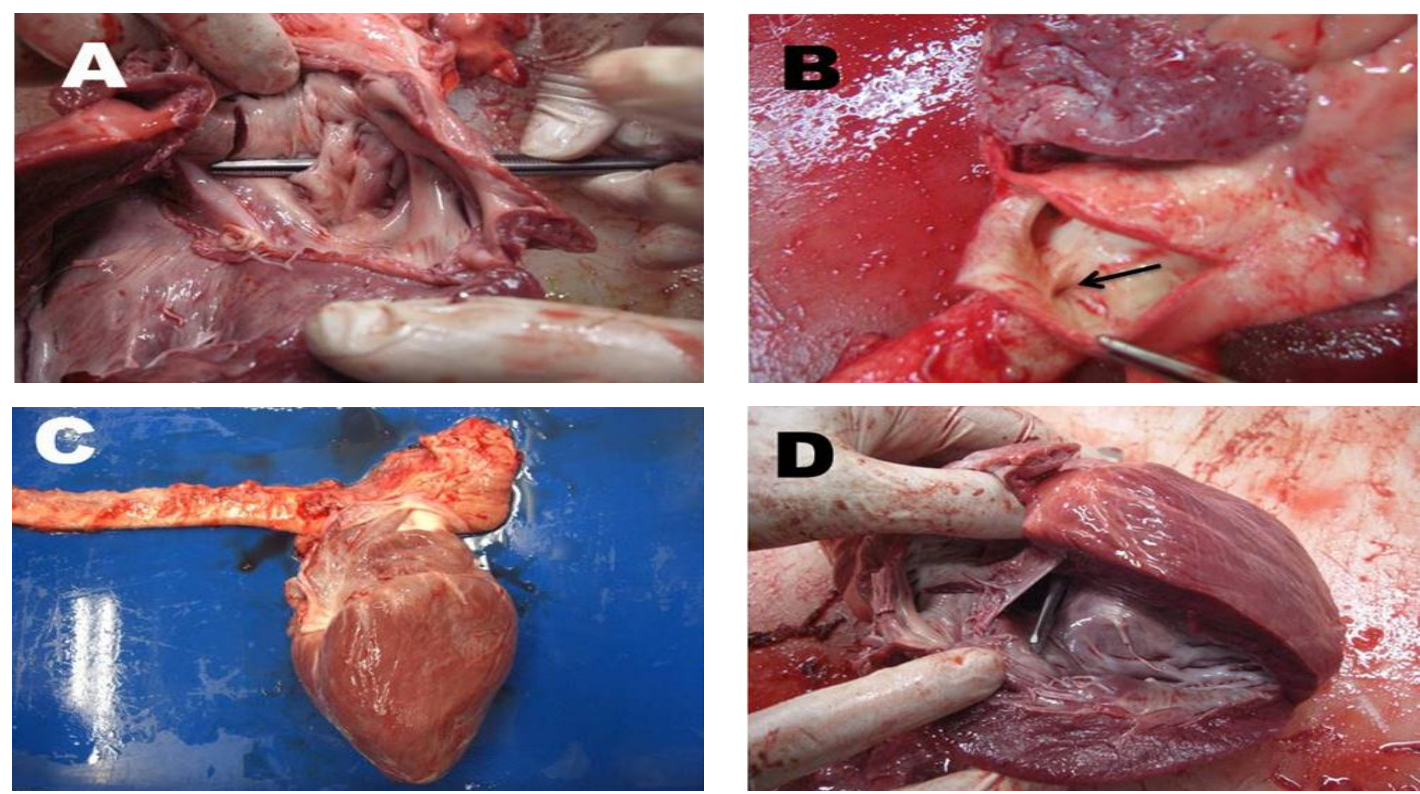

Fig. 1 (A-D): Hearts of necropsied calves. Gross pictures show: (A) PFO as an opening between both atria, (B) PDA as an opening of ductus arteriosus inside pulmonary artery (arrow), (C) dextroposition of the aorta and (D) VSD as an opening in the upper part of the membranous septum near the aortic root.
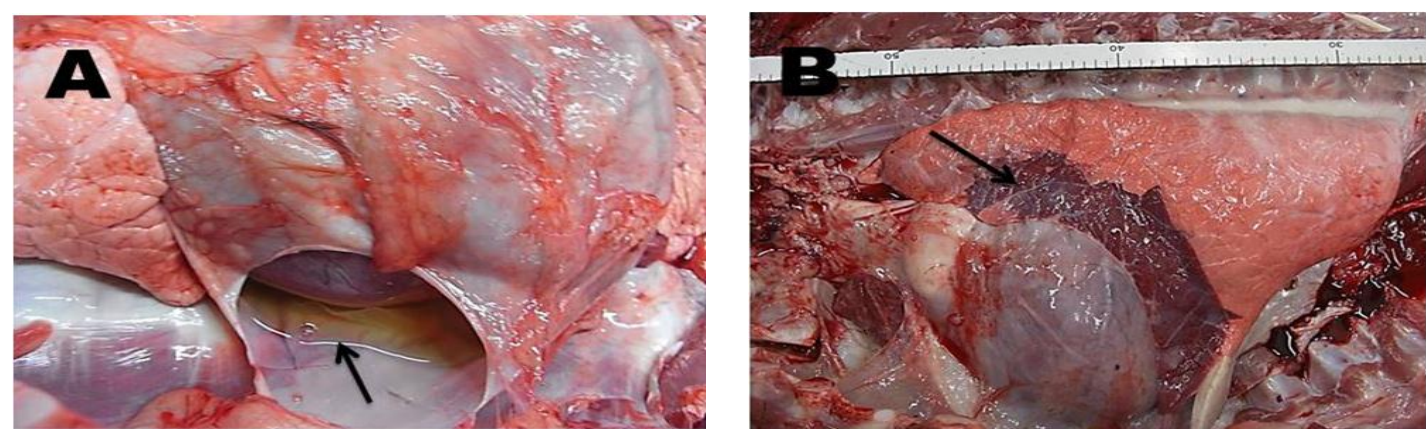

Fig.2: (A): Heart of a necropsied calf. Gross picture shows hydropericardium (arrow). (B): Lung of a necropsied calf. Gross picture shows atelectatic cranioventral portion of diaphragmatic lobe (arrow).
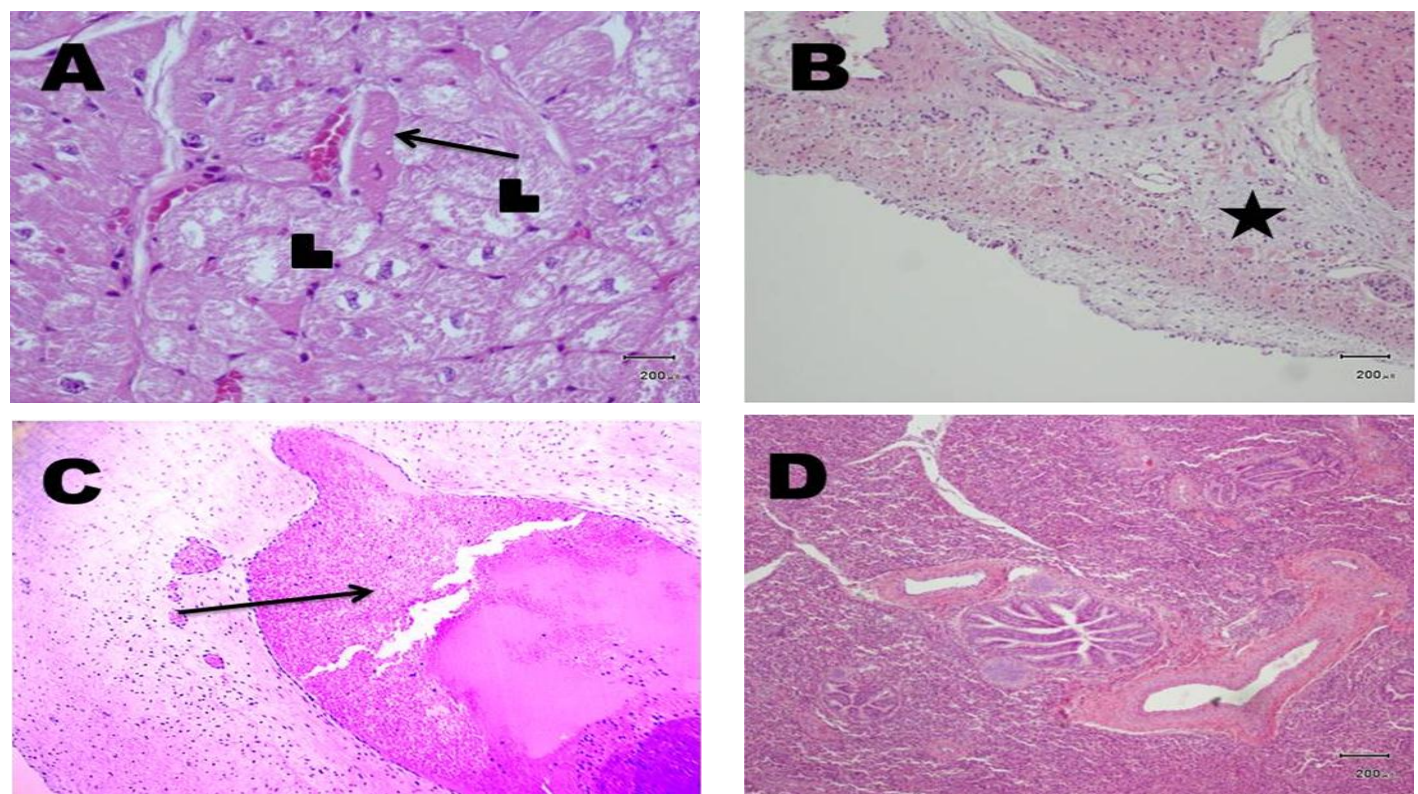

Fig. 3: Heart of a necropsied calf shows (A): hyaline degeneration (arrow) and hydropic degeneration (arrowheads) and (B): edema and leukocytic infiltration in pericardium. (C): Auriculo-ventricular valve shows hematoma lined by flattened cells (arrow) surrounded by congested capillaries. (D): Lung shows diffuse atelectasis characterized by collapsed alveoli with slit like appearance (H\&E). 

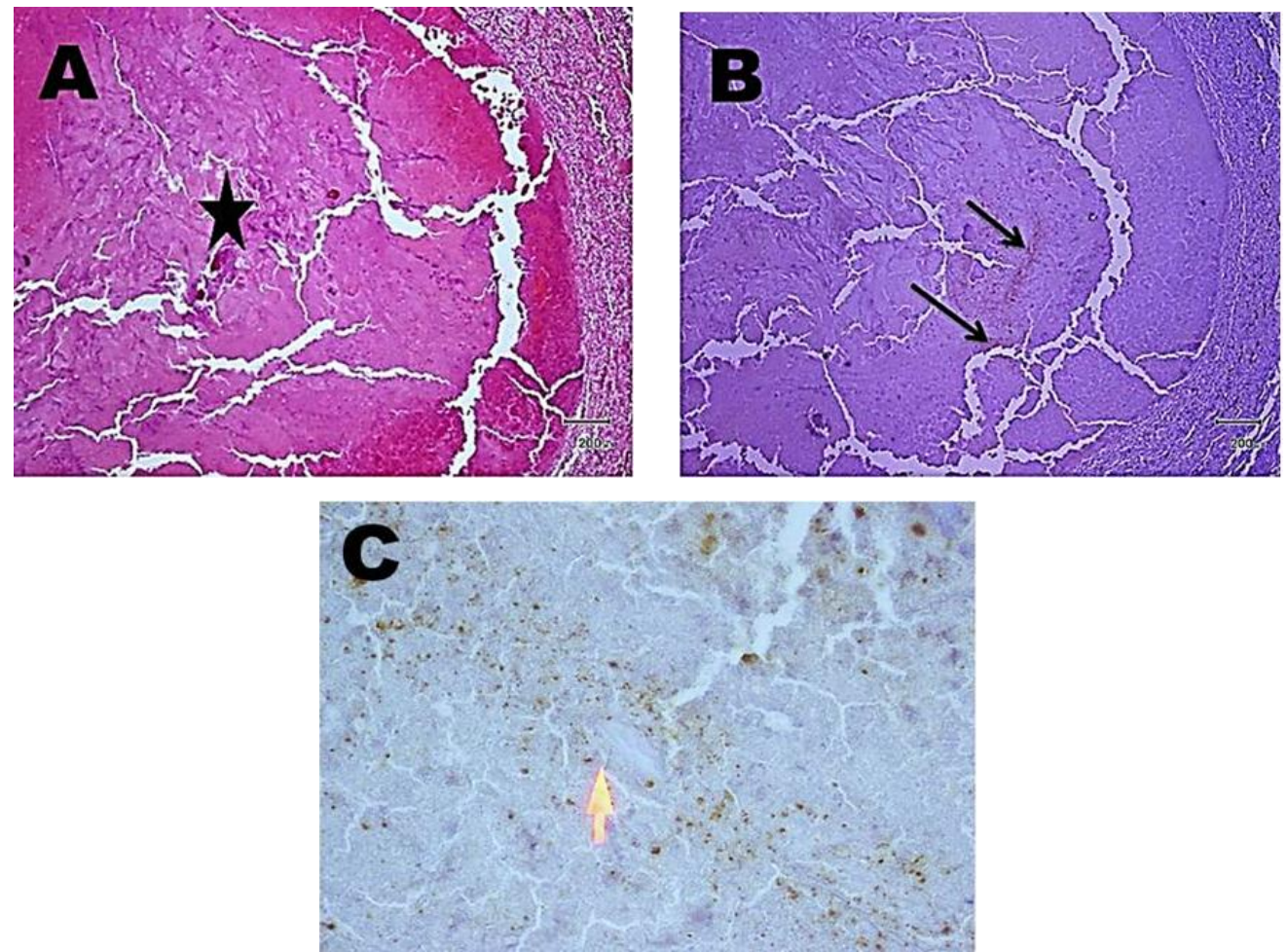

Fig. 4(A-C): Microscopic picture of Lung shows (A): necrotizing bronchitis characterized by accumulation of caseated necrotic material and basophilic bacterial colonies in lumen of bronchus (asterisk) H\&E. Positive brown immunolabelling for P. multocida inside necrotic material is seen as indicated by (black arrows) in (B) and (yellow arrow) in (C) (IHC counterstained with Mayer's hematoxylin)
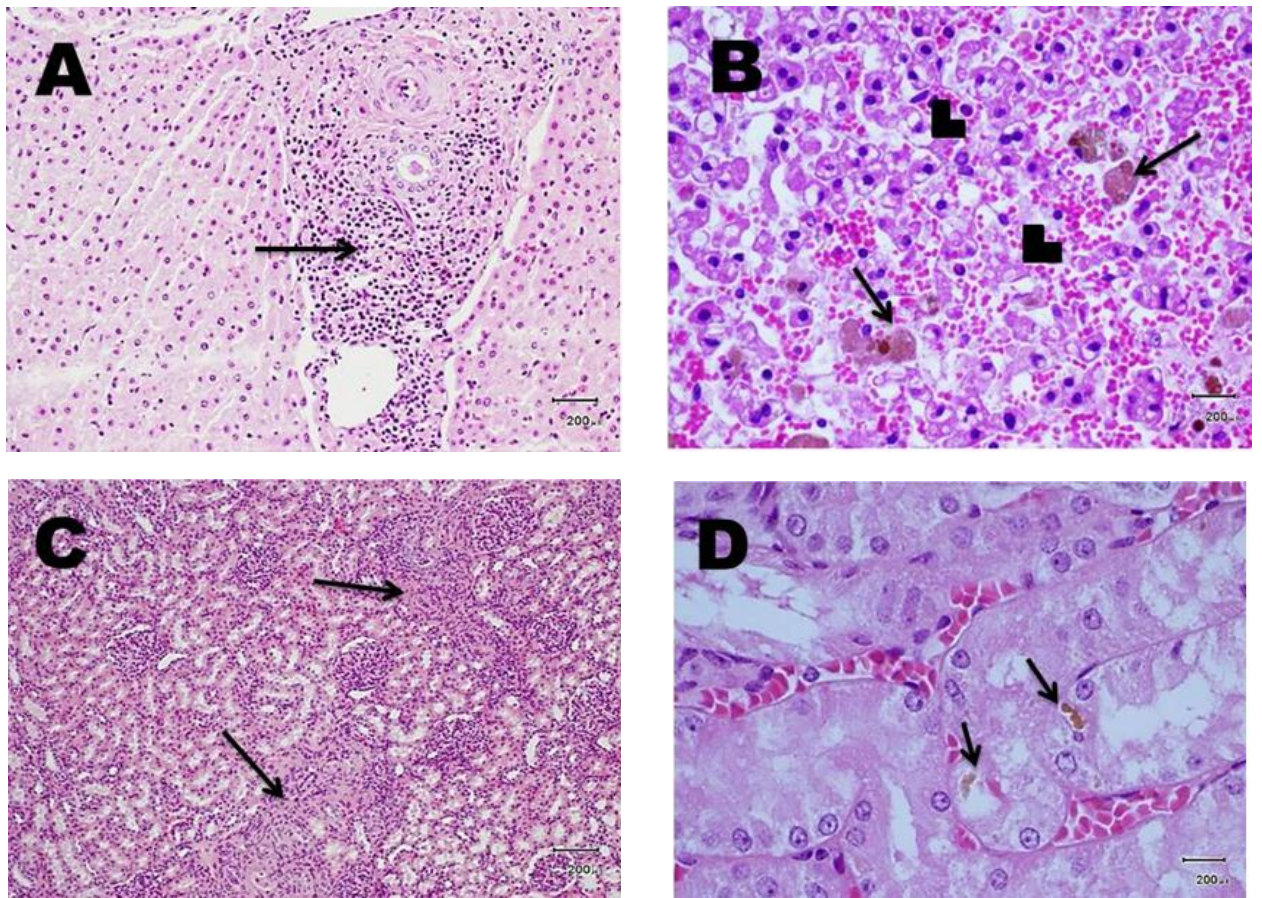

Fig. 5: Liver of necropsied calf shows (A) MNCs with eosinophils infiltration and mild fibrous tissue proliferation in portal area (arrow), (B) vacuolar degeneration in hepatocytes (arrowheads), dilated sinusoids with RBCs and brown hemosiderin pigment (arrows). Kidney of necropsied calf shows (C) chronic interstitial nephritis characterized by multifocal interstitial MNCs aggregation and fibrosis (arrows) and (D) brown lipofuscin pigment inside renal epithelium (arrows) H\&E. 

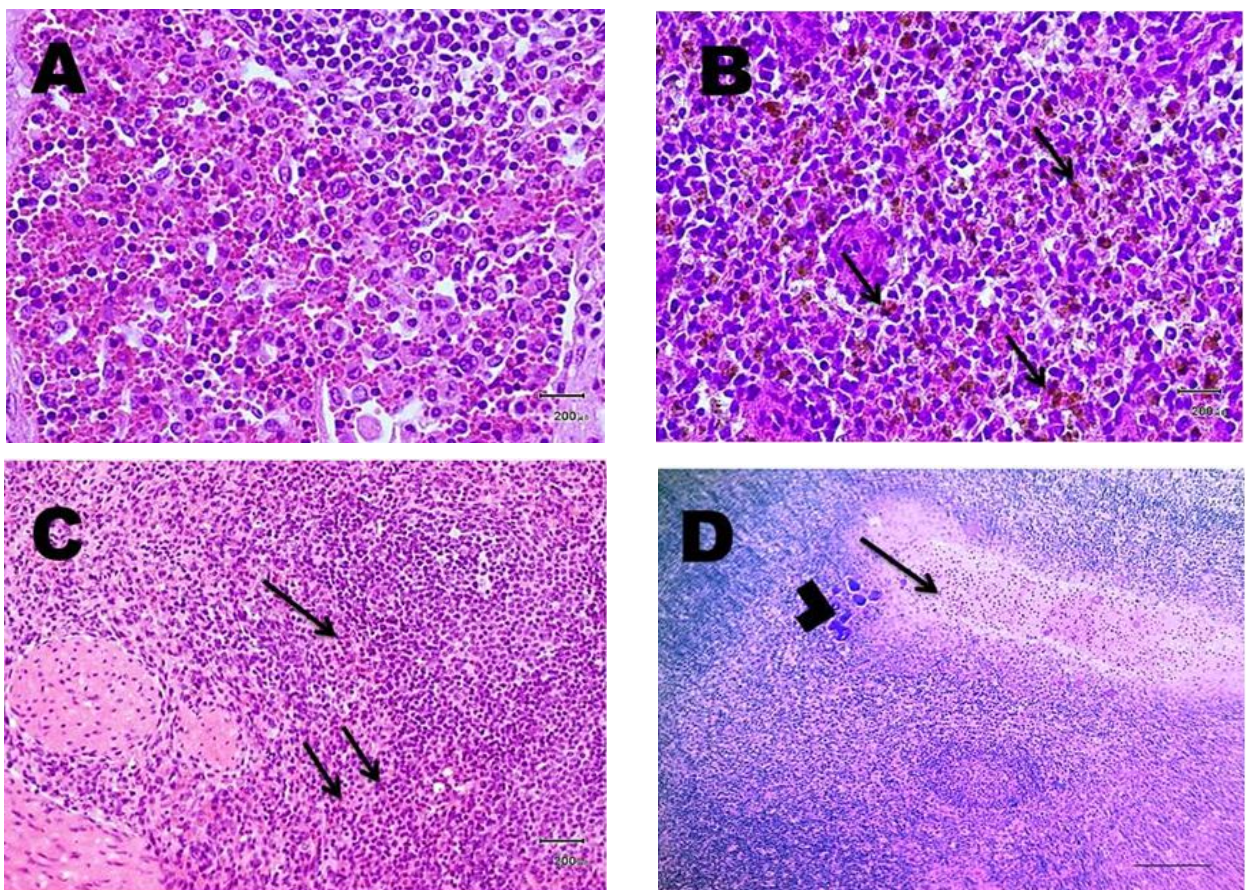

Fig. 6: Spleen of necropsied calf shows (A) hemorrhage, $(\mathbf{B})$ hemosiderosis in red pulp and $(\mathbf{C})$ perifollicular granulocytosis. Tonsils of necropsied calf show (D) crypt abscess (arrow) with foci of dystrophic calcification and (arrowhead). H\&E
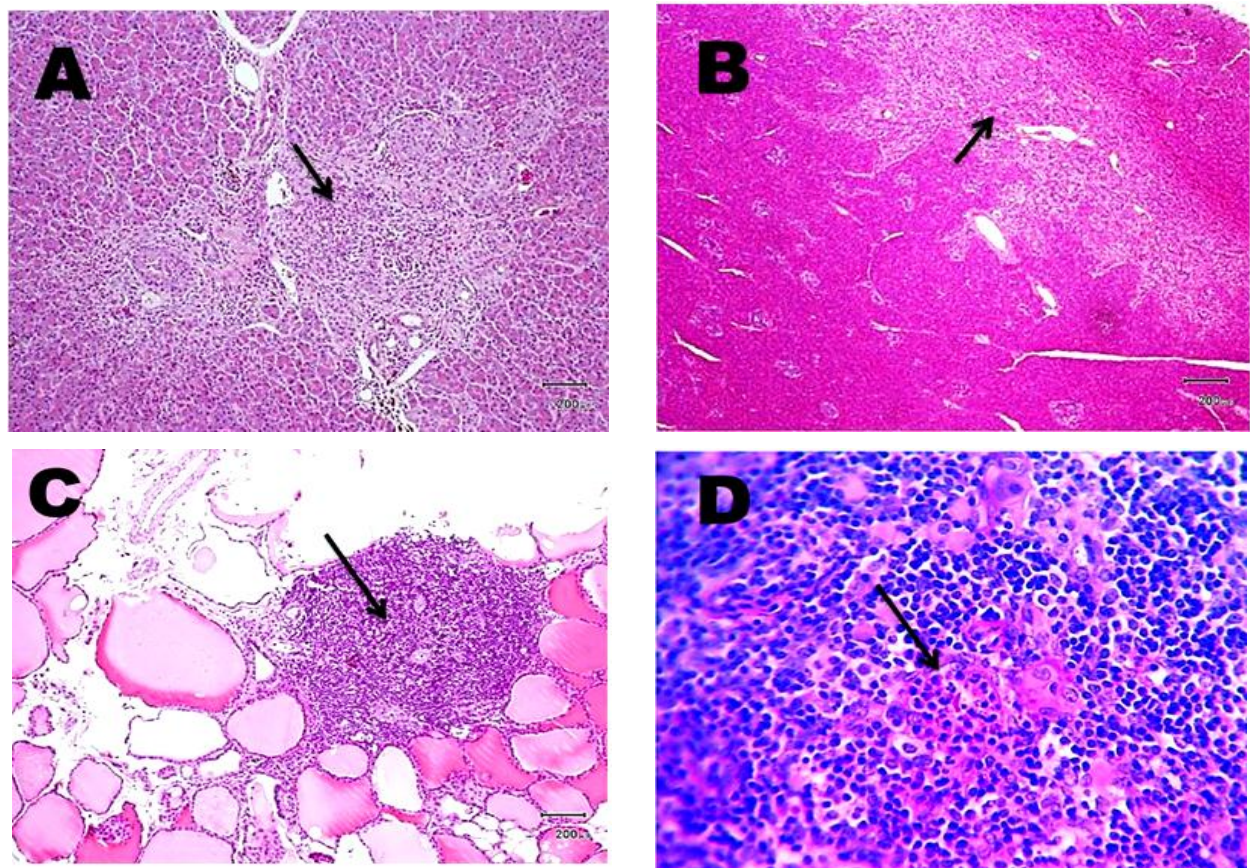

Fig. 7: (A\&B) Pancreas shows (A) interstitial fibrosis and (B) remnant of primary islets. (C) Thyroid gland: shows nodular lymphocytic aggregation (arrow). (D) Thymus shows extra medullary hematopoiesis (arrow) H\&E.

\section{DISCUSSION}

In this study we reported CHD in 4 necropsied calves. Clinical signs of CHD were similar to those reported by Jafari Dehkordi and Hoseini (2016). All septal defects were high in location and ranged from 5 to 35 $\mathrm{mm}$ in diameter. VSD was previously described in 2 calves with focal fibrosis of the ventricular endocardium, mitral, and aortic valves without infection (Buczinski et al., 2006). VSD is most frequently located in the membranous part of the interventricular septum, adjacent to the aortic valve (Radostits et al., 2000; Reef and McGuirk, 2002), and it causes free shunting of blood between the ventricles. Blood from the left ventricle is shunted towards the right ventricle and pulmonary arteries. 
The excessive volume-flow overloads the pulmonary vascular tree and can lead to pulmonary hypertension (McGuirk et al., 1984; Bonagura and Darke 1995). Since shunting occurs from left to right, the left heart demonstrates morphological changes typical of volume-flow overload (left atrial and left ventricle enlargement). When the pulmonary pressure exceeds the systemic pressure, reversal of the shunt may occur. That phenomenon was called the Eisenmenger's complex. Calves with a VSD usually had clinical signs of heart failure (Cordy and Ribelin, 1950; Belling 1961 and 1962; Sandusky and Smith 1981; West, 1988; Gavaghan et al., 2001, Schwarzwald et al., 2003). In some situations, the condition may occur without any clinical signs other than a cardiac murmur (Pipers et al., 1985; Penrith et al., 1994). VSD can damage the endocardium by blood flow turbulences and predispose to bacterial endocarditis (Brickner and Hillis 2000; Buczinski et al., 2006). This complication of VSD has been reported in a goat (Parry et al., 1982) and in a Holstein heifer (Besser and Knowlen, 1992). In our findings, pulmonary infection was detected instead. In PDA there was a significant left-to-right shunt which generated a large left ventricular volume overload. When the response of left ventricle failed dilation (primarily) and hypertrophy developed. These processes resulted in pulmonary hypertension and congestion. The right ventricle can be affected by the pulmonary pressure load and right ventricular hypertrophy can also develop. If the pulmonary resistance equals or exceeds the systemic vascular resistance, a right-to-left shunt happens (Radostitis et al., 2007; Smith 2009). Here we described histopathology of tissues in CHD affected calves. In this report, extramedullary hematopoiesis and chronic interstitial nephritis were constant findings. Chronic kidney disease was reported in children with CHD (Morgan et al., 2015). Chronic hypoxia was suggested to be the cause of both lesions. In cyanotic congenital heart disease, chronic hypoxia stimulates erythrocytosis through the stimulation of erythropoeitin resulting in the increase of blood viscosity (DeFilippis et al., 2007; Cordina and Celermajer 2010; Pichon et al., 2012). Hyperviscosity influenced renal hemodynamics resulting in increased glomerular filtration (Nashat and Portal, 1967). The increased filtration fraction led to chronic nephropathological changes including glomerulosclerosis (Shankland et al., 1994; Blantz and Gabbai, 1989). In addition, chronic hypoxia for 28 days in rats induced tissue changes including abnormal renal tubular structure and interstitial fibrosis (Truong et al., 1992).

\section{CONCLUSION}

Extramedullary hematopoiesis in liver and lymphoid organs and chronic interstitial nephritis were constant findings in CHD affected calves.

\section{ACKNOWLEDGMENT}

We acknowledge efforts of Dr. Amal Awad; Department of Bacteriology, Mycology and Immunology, Faculty of Veterinary Medicine, Mansoura University for carrying out bacterial isolation.

\section{REFERENCES}

Awadin, W.; Hussein, H.S. and Hidefumi, F. (2012): Some pathological and immunohistochemical studies on Pasteurella multocida and Arcanobacterium pyogenes in bovine lungs. $7^{\text {th }}$ Int.Sci. Conf., Mansoura: 151-160.

Belling, T.H. (1962): Genetic effect of cardiac ventricular septal defect in Hereford cattle. Vet. Med. 965-968.

Belling, T.H. (1961): Ventricular septal defect in the bovine heart. A report of three cases. J. Am. Vet. Med. Assoc. 138:595-598.

Besser, T.E. and Knowlen, G.G. (1992): Ventricular septal defects in bovine twins. J Am. Vet. Med. Assoc. 200: 1355-1356.

Blantz, R.C. and Gabbai, F.B. (1989): Glomerular hemodynamics in pathophysiologic conditions. Am. J. Hypertens. 211( $\mathrm{Pt} 2)$ : 208S-12.

Bonagura, J.D. and Darke, P.G. (1995): Congenital heart disease. In: Ettinger SJ, Feldman EC, eds. Textbook of Veterinary Internal Medicine. Diseases of the dog and cat. 5th ed. Philadelphia, WB Saunders, 892-943.

Brickner, M.E. and Hillis, L.D. (2000): Congenital heart diseases in adults. First of two parts. New Eng. J. Med. 42: 256-263

Buczinski, S.; Fecteau, G. and DiFruscia, R. (2006): Ventricular septal defects in cattle: 25 cases. Can. Vet. J. 47: 246-252.

Cordina, R.L. and Celermajer, D.S. (2010): Chronic cyanosis and vascular function: implications for patients with cyanotic congenital heart disease. Cardiol Young. 203: 242-53.

Cordy, D.R. and Ribelin, W.E. (1950): Six congenital cardiac anomalies in animals. Cornell Vet. 40: 249-256.

DeFilippis, A.P.; Law, K.; Curtin S. and Eckman, J.R. (2007): Blood is thicker than water: the management of hyperviscosity in adults with cyanotic heart disease. Cardiol. Rev. 151: 314.

Gavaghan, B.J.; Kittleson, M.D. and Decock, H. (2001): Eisenmenger's complex in a HolsteinFriesian cow. Aust. Vet. J. 79: 37-40.

Gournay, V. (2011): The ductus arteriosus: Physiology, regulation, and functional and congenital anomalies. Arch Cardiovasc. Dis. 104(11): 578-585.

Gopal, T.; Leipold, H.W. and Dennis, S.M. (1986): Congenital cardiac defects in calves. Am. J. Vet. Res. 47(5): 1120-1. 
Fischer, E.W. and Pirie, H.M. (1965): Cardiovascular lesions in cattle. Ann. NY Acad. Sci. 127: 606-622.

Friedman, W.F. (1988): Congenital heart disease in infancy and childhood. In: Braunwald E, ed. Heart Disease. A textbook of cardiovascular medicine, 3th ed. Philadelphia: WB Saunders, 896-975.

Jafari Dehkordi, A. and Hoseini, F. (2016): Patent ductus arteriosus in a lamb: Vet. Res. Forum. 7 (1) $85-88$.

Jafari Dehkordi, A.; Fatahian Dehkordi, R.A. and Borjan, A. (2010): An unusual congenital anomaly in the pulmonary artery and vein of a Holstein calf. Comp. Clin. Path.19: 611-613.

Lee, B.H. and Kim, W.G. (2004): A case of patent ductus arteriosus in a holstein calf. J. Vet. Sci. 5(1): 83-84

Leipold, H.W.; Dennis, S.M. and Huston, K. (1972): Congenital defects in cattle: nature, cause and effect. Adv. Vet. Sci. Comp. Med. 16: 103150.

McGuirk, S.M.; Welker, F.H.; Muir, W.W. and Hull, B.L. (1984): Thermodilution curves for diagnosis of ventricular septal defect in cattle. J. Am. Vet. Med. Assoc. 184: 11411145.

Morgan, C.; Al-Aklabi, M. and Guerra, G.C. (2015): Chronic kidney disease in congenital heart disease patients: a narrative review of evidence. Can. J. Kidney Health Dis. 2: 27

Nashat, F.S. and Portal, R.W. (1967): The effects of changes in haematocrit on renal function. $\mathrm{J}$. Physiol. 1933: 513-22.

Ohwada, K. and Murakami, T. (2000): Morphologies of 469 cases of congenital heart diseases in cattle. J. Jap. Vet. Med. Assoc. 53: 205-209.

Parry, B.W.; Wrigley, R.H. and Reuter, R.E. (1982): Ventricular septal defects in three familiallyrelated female Saanen goats. Aust. Vet. J. 59: 72-76.

Pichon, A.; Connes, P.; Quidu, P.; Marchant, D.; Brunet, J.; Levy, B.I.; Vilar, J.; Safeukui, I.; Cymbalista, F.; Maignan, M.; Richalet, J.P. and Favret, F. (2012): Acetazolamide and chronic hypoxia: effects on haemorheology and pulmonary haemodynamics. Eur. Respir. J. 406: 1401-9.
Pipers, F.S.; Reef, V.B. and Wilson, J. (1985): Echocardiographic detection of ventricular septal defects in large animals. J. Am. Vet. Med. Assoc. 187: 810-816.

Penrith, M.L.; Bastianello, S.S. and Petzer, I.M. (1994): Congenital cardiac defects in two closely related Jersey calves. J. S. Afr. Vet. Assoc. 65: 31-35.

Reef, V.B. and McGuirk, S.M. (2002): Diseases of the cardiovascular system. In: Smith BP, ed. Large Animal Internal Medicine. 3rd ed. Mosby, StLouis: pp.443-478.

Radostits, O.M.; Gay, C.G.; Blood, D.C. and Hinchcliff, K.W. (2000): Congenital cardiac defects. In: Radostits OM, Gay CG, Blood DC, Hinchcliff KW, eds. Veterinary Medicine. A textbook of the diseases of cattle, sheep, pigs, goats and horses. 9th ed. Philadelphia, WB Saunders: pp. 391-394.

Radostitis, O.M.; Gay, C.C.; Blood, D.C. and Hinchcliff, K.W. (2007): Veterinary medicine: A textbook of the diseases of cattle, sheep, pigs, goats and horses. 10th ed. Philadelphia, USA: Saunders Elsevier; pp. 431-433.

Sandusky, G.E. and Smith, C.W. (1981): Congenital cardiac anomalies in calves. Vet Rec. 108: 163-165.

Schwarzwald, C.; Gerspach, C.; Glaus, T.; Scharf, G. and Jenni, R. (2003): Persistant truncus arteriosus and patent foramen ovale in a Simmentaler $x$ Braunvieh calf. Vet. Rec. 152:329-333.

Shankland, S.J.; Ly, H.; Thai, K. and Scholey, J.W. (1994): Increased glomerular capillary pressure alters glomerular cytokine expression. Circ. Res. 755: 844-53.

Smith, B.P. (2009): Large animal internal medicine. 4th ed. St. Louis, USA: Mosby Elsevier. pp. 457-463.

Truong, L.D.; Farhood, A.; Tasby, J. and Gillum, D. (1992): Experimental chronic renal ischemia: morphologic and immunologic studies. Kidney Int. 416: 1676-89

Van Nie, C.J. (1966): Congenital malformations of the heart in cattle and swine. Acta Morphol. Neerl. Scand. 6: 387-393.

West, H.J. (1988): Congenital anomalies of the bovine heart. Br. Vet. J. 144: 123-130.

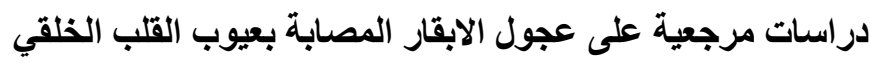

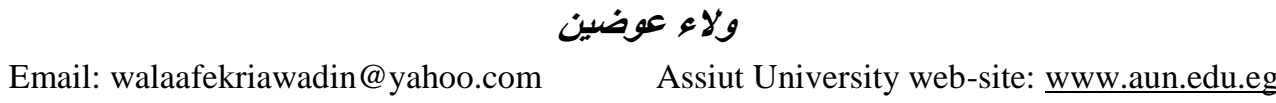

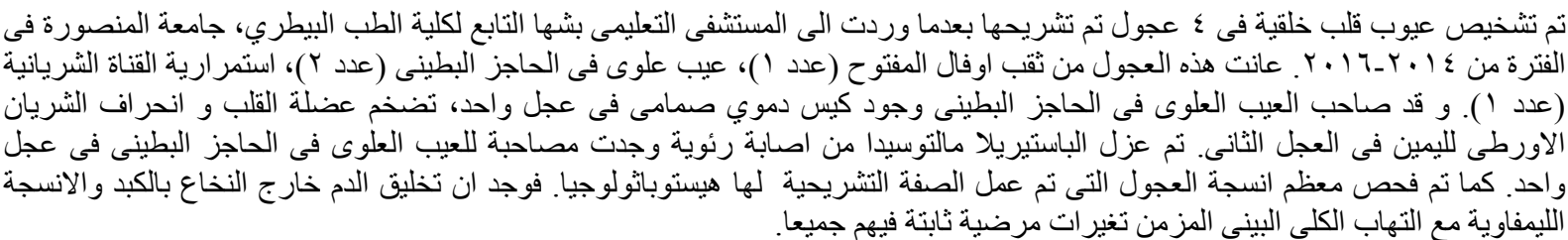

